\title{
A significação da joia na contemporaneidade:
}

\section{a percepção do consumidor e a produção de sentido das} marcas

\section{The signification of jewelry in contemporary times:}

\section{the perception of the consumer and the production of brand sense}

Clotilde Perez

Doutora em Comunicação e Semiótica pela PUC-SP e professora de Publicidade e Semiótica da ECA-USP. Universidade de São Paulo, Escola de Comunicação e Artes, São Paulo (SP), Brasil.

Bruno Pompeu

Doutor em Ciências da Comunicação (USP) e professor de Publicidade e Propaganda (ECA-USP e ESPM-SP). Universidade de São Paulo, Escola de Comunicação e Artes, São Paulo (SP), Brasil.

Introdução

Poucas categorias de produto são tão representativas e expressivas das dinâmicas complexas ligadas ao fenômeno do consumo quanto a das joias. Menos ainda conseguem ser ao mesmo tempo tão exemplares de tudo aquilo que envolve, suscita, permite, provoca e proporciona o design. Falar de joias em termos teóricos é caminhar pelas tortuosas vias que tangenciam a produção de sentido e a busca por satisfação de necessidades, a capacidade humana de amalgamar significados em coisas e o emprego de produtos para a conexão com determinados valores culturalmente constituídos. Basicamente, é disso que 
trata esse artigo, explorando ainda a relação direta desses assuntos com os desafios que enfrenta hoje a comunicação publicitária contemporânea no que se refere à sua função cultural de construtor simbólico, produtor de sentido e articulador de padrões estéticos, comportamentais e éticos.

Em um momento em que o consumo da joia, ou seja, dos produtos de uma categoria de mercado tão expressiva simbolicamente - já que lida com objetos que combinam tão emblematicamente a dimensão material, do metal e da pedra, com o plano do simbólico, do luxo e do sonho - se vê em declínio e se realiza uma pesquisa no intuito de se compreenderem as razões para isso e, mais importante, as eventuais saídas dessa condição, a possibilidade de se articular o conhecimento empírico e mercadológico com o conhecimento teórico e acadêmico nos parece bastante enriquecedora. É nesse contexto que surge este artigo, que nos parece ter relevância justamente na proposta de se entenderem os processos complexos que desembocam no consumo a partir de uma base teórica ampla, que combina comunicação, marketing e consumo, com uma empreitada empírica de fôlego, que passa pela pesquisa junto ao consumidor e pela análise de materiais de marca, conforme destacado adiante.

Embora estudos sobre motivações ao consumo moldadas pela cultura, expressas em comportamentos e identificadas pelos procedimentos do marketing em diferentes segmentos do mercado sejam muitos e bastante abrangentes (ARAUJO \& TINOCO, 2015 e MELO et al., 2016, PEREZ, 2020, por exemplo), o presente trabalho se justifica também por apresentar abordagem predominantemente qualitativa, de caráter interpretativo, que procura contribuir simultaneamente tanto com o pensamento tipicamente mercadológico quanto com a reflexão acadêmica. A ideia é aproximar o pensamento que se desdobra em práticas e métodos de mercado, a partir dos entendimentos das motivações do consumidor contemporâneo, da reflexão mais acadêmica do campo da comunicação, comprometida com o entendimento das dinâmicas e das práticas sociais estabelecidas e moldadas pelo consumo.

Não é objetivo específico deste artigo revisitar a longa - e interessante - história da joia ou da joalheria. Aos que queiram se inteirar sobre o assunto, há ótimas obras brasileiras a se recomendar (GOLA, 2008; DAYÉ et al., 2017; SOARES, 2001; SANTOS, 2001; MOL, 2009), dedicadas aos estudos históricos gerais e regionais da joia. Há também importantes publicações internacionais (EICHHORN-JOHANNSEN et al., 2013; TAIT, 2008; BLACK, 1998), todas dando conta da evolução técnica da joalheria, dos primórdios aos dias atuais, entrelaçada ao próprio desenvolvimento histórico e cultural da humanidade. 
O que nos interessa destacar, entretanto, é que a joia, com o próprio advento do design dito moderno, a partir do fim do século XIX e começo do século XX, se conecta profundamente com o universo do consumo.

Entre 1850 e 1930, aproximadamente, três gerações de novos profissionais - alguns já apelidados de "designers" - dedicaram seus esforços à imensa tarefa de conformar a estrutura e a aparência dos artefatos de modo que ficassem atraentes e eficientes. Sua meta era nada menos do que reconfigurar o mundo, com conforto e bem-estar para todos. (CARDOSO, 2012, p. 16)

O autor se refere aos impactos mais diretos da revolução industrial na casa, no corpo e no cotidiano das pessoas, por meio da fabricação em larga escala dos mais variados produtos. Móveis, utensílios, pequenos aparelhos, tudo passou a ser produzido por aquela nascente e promissora indústria. "Indústrias crescentemente mecanizadas produzem em escala, padronizando componentes, operando processos e linhas de montagem, estudando tempos e métodos e conquistando, assim, substanciais aumentos de produção" (PIRATININGA, 1994, p. 8). E, nesse contexto, a joia - uma vez que está sustentada na dimensão estética dos materiais, na complexidade e na sofisticação dos processos produtivos, ganhando sentido por estar inserida nas dinâmicas da cultura - parece se encontrar definitivamente com o mundo que ela mesma tanto tempo antes já havia demonstrado existir: um mundo sustentado na lógica produçãoconsumo, com os produtos (bens ou mercadorias, como queiram, agora conformados pelo design) servindo como demarcadores sociais, demonstrações de poder, veículos para sentidos e valores; enfim, como signos.

E, como todo signo - fadado, como já vaticinara Peirce (1993), a se expandir e se tornar mais complexo -, a joia atravessa a era moderna e chega aos fins do século XX e inícios do XXI carregada de sentidos aparentemente antagônicos no seu processo cultural de significação, porém absolutamente consistentes do ponto de vista humano-histórico-social. Em outras palavras: já em um contexto mais próximo do que depois viria a ser chamado de sociedade de consumo, a joia assume sentidos de diferenciação, poder, demarcação social, ostentação e expressão da identidade; ao mesmo tempo que, cumprindo fidelidade à sua origem mais ancestral, mantém seus sentidos originais de permanência, transcendência, compromisso, concretude e vínculo.

Em um mundo que dá claros sinais de sofrimento com valores como efemeridade, instantaneidade, insegurança, superficialidade e profunda crise moral (BAUMAN, 2001 e 2008; LIPOVETSKY, 2004 e 2007; LYOTARD, 2010; GIDDENS, 1991; HAN, 2017), parece interessante imaginar que a joia poderia ser a 


\section{ALCEU}

ISSN: $2175-7402$

"solução perfeita", o produto mais atraente do ponto de vista simbólico, sendo buscado intensamente pelos cidadãos consumidores. No entanto, não é o que acontece. Mas por que não é assim? Por que o setor está em crise? Há algum tipo de rejeição? As pessoas não querem mais usar joias? O jovem não usa joia? Essas foram algumas das questões que levaram diversas entidades do setor (IBGM, Ajorio, Ajesp e Ajomig, associações de joalheiros do Rio de Janeiro, São Paulo e Minas Gerais) a demandar a pesquisa "Significações", que agora se desdobra neste artigo.

Não, não pode se tratar apenas de uma questão de violência urbana, já que carros, celulares e outros produtos sabidamente visados pelos bandidos seguem sendo consumidos normalmente. Tampouco se pode creditar tal diminuição das vendas a um contexto econômico desfavorável, já que estamos falando de um declínio que antecede a crise atual e, como se sabe, falta de dinheiro nunca foi impedimento para impulsos consumistas. Descartadas as primeiras hipóteses mais óbvias, partimos para o planejamento e a execução da pesquisa, cujos resultados mais conceituais - sobre comunicação e consumo - e as reflexões decorrentes - sobre o contexto atual - compartilhamos a seguir.

Nosso objetivo neste trabalho é apresentar uma discussão acerca do consumo da joia, em uma interface teórica com os estudos do consumo e da comunicação publicitária, procurando evidenciar a centralidade desses temas no entendimento dos dilemas típicos da contemporaneidade. Queremos demonstrar, a partir dos resultados da pesquisa já citada, de que forma o consumo e a comunicação neste caso, das joias, mas com evidente efeito semelhante em outras áreas e segmentos - se entrelaçam nos dias atuais como importante instrumento de construção, transformação, desenvolvimento e aquisição de sentido.

\section{Metodologia da pesquisa}

O percurso investigativo começou pelo aprofundamento teórico acerca dos sentidos históricos e contemporâneos da joia em nossa cultura, especificamente tendo em conta o contexto brasileiro. Nesse sentido, conforme já indicado acima, diversos autores e obras, brasileiros e estrangeiros, trouxeram destacadas contribuições. Também foram estudados os anuários e os relatórios de tendências em Joias do IBGM - Instituto Brasileiro de Gemas e Metais (em parceria com a Apex - Agência Brasileira de Promoção de exportação e investimentos) e os relatórios Brazil Expression e É do Rio! Publicação da AjoRio Associação dos Joalheiros do Rio de Janeiro. Também foi consultado o relatório da "Pesquisa Nacional do 


\section{ALCEU}

ISSN: $2175-7402$

Mercado Consumidor de Joias", com os conteúdos da pesquisa realizada em 2005, pela Ajesp em parceria com o IBGM. Todos esses relatórios compuseram a investigação documental e trouxeram contribuições importantes à reflexão teórica já iniciada. Foi a partir do escrutínio desse material, por exemplo, que se chegou ao entendimento de como se forma e se estrutura o mercado brasileiro de joias.

A pesquisa empírica foi robusta, e o planejamento se divide basicamente em duas frentes: (1) pesquisa junto ao público, com entrevistas em profundidade e grupos de discussão; e (2) análise semiótica de marcas de joias selecionadas a partir da lista de marcas mais citadas nos grupos e nas entrevistas.

Assim, foram realizados três grupos de discussão (COSTA, 2012) com consumidoras mulheres de diferentes faixas etárias e com perfis de consumo também distintos:

- Lovers mais jovens (15 a 17 anos): meninas que, apesar da pouca idade, demonstram gosto pela joalheria, consumindo produtos desse segmento. Ainda que se trate de um perfil menos frequente, a ideia era justamente entender quais teriam sido as motivações e os valores atrativos para essa rara aproximação;

- Lovers mais velhas (24 a 35 anos): mulheres que, apesar da já mencionada tendência ao declínio do consumo de joias, mantêm esse hábito e esse gosto. $\mathrm{O}$ intuito foi identificar quais mecanismos teriam funcionado na manutenção desse tipo de vínculo, que valores seguem sendo desejados;

- Não usuárias mais velhas (24 a 35 anos): mulheres que, sem "odiar" joias (não "haters"), por alguma razão deixaram de consumir tais produtos (abandonadoras). Evidentemente, o objetivo neste caso era verificar o que teria feito com que os vínculos de consumo se rompessem e, ao mesmo tempo, que fatores teriam atraído sua preferência para outras categorias de produtos.

Cada grupo foi composto por 7 consumidoras, selecionadas a partir do recrutamento de 9 , garantindo a qualidade do perfil desejado. A escolha das mulheres para a realização está fundamentada no total predomínio no segmento de joias, tanto compra quanto uso, conforme relatório Pesquisa Nacional de Joia IBGM (2005), ainda que se observe crescimento da compra e consumo por parte do público masculino. O roteiro privilegiou o entendimento da concepção da joia e os diferentes rituais de compra, uso e posse, nos distintos perfis de consumidoras, permeado por estimulações diretas e exercícios projetivos. Além de tarefa (pré-work) levada aos grupos por meio de fotos que foram apresentadas e debatidas durante as 


\section{ALCEU}

ISSN: $2175-7402$

dinâmicas, como foco no uso e posse (guarda) das joias. Os grupos aconteceram no mês de agosto de 2018, em ambiente e condições propícios.

Como os grupos de discussão acabaram privilegiando mulheres de uma faixa etária no geral mais jovem, expandimos o campo para outros perfis de consumidoras por meio de entrevistas em profundidade (MEDINA, 1990; YASUDA \& OLIVEIRA, 2012, p. 79; MALHOTRA, 2012, p. 121; DUARTE, 2012; e BAUER \& GASKELL, 2010, p. 64).

Foram entrevistadas três mulheres mais velhas (45 a 70 anos), com o objetivo de identificar possíveis diferenças nos sentidos que a joia ocupa em suas vidas. Adicionalmente, foram realizadas seis outras entrevistas em profundidade com experientes vendedoras do setor - selecionadas por conveniência a partir de indicação das instituições do setor -, tanto de lojas físicas quanto aquelas que vendem joias em ateliês fechados, uma vez que são perfis muito distintos de exposição e comercialização de produtos. O objetivo com estas entrevistas era entender, a partir da perspectiva da produção/comercialização, qual é o lugar da joia na atualidade, quais são as principais forças e argumentos de venda, bem como as fragilidades e empecilhos à comercialização. Procuramos também, a partir dessas entrevistas, discutir aspectos comunicacionais das lojas, tais como vitrina, merchandising, embalagem, site, catálogo, redes sociais etc. As entrevistas aconteceram nos meses de outubro e novembro de 2018.

Concluindo o esforço empírico planejado e executado, não mais se valendo do consumidor como fonte de informação (foco na recepção), mas agora debruçando interesse sobre o próprio mercado (foco na emissão), chegamos às análises semióticas. Tendo por base C. S. Peirce (1999) e Santaella (2004a e 2004b), analisamos materiais comunicacionais das marcas - anúncios publicados em revistas, posts em redes sociais e páginas na internet, fornecidos pelas instituições viabilizadoras do estudo. Tais materiais nos permitiram incluir na análise elementos das duas dimensões da marca disponíveis ao olhar do investigador: suas expressividades (logo, nome, cor...) e ao mesmo tempo sua oferta (produtos, coleções, lojas...).

É nessas definições e classificações [do signo, proposta por Peirce], portanto, que podem ser buscados os princípios norteadores para o método de análise todas as formas de expressão das imagens e marcas: nome, cor, som, logotipo, embalagem..., em qualquer meio que estas possam aparecer... (PEREZ, 2004, p. 151) 


\section{ALCEU}

ISSN: 2175-7402

Em termos gerais, o percurso protocolar de análise se deu a partir das três categorias fundamentais da semiótica de Peirce - primeiridade, secundidade e terceiridade -, expressas, neste caso, a partir dos preceitos da sua gramática especulativa respectivamente nos planos qualitativo-icônico, singular-indicial e convencional-simbólico. De modo que tenha sido possível avaliar, sob os mesmos procedimentos, materiais distintos, como os citados acima. As marcas escolhidas foram: H.Stern, Pandora, Swarovski, Tiffany, Vivara, Cartier e Manoel Bernardes, usando como critério de seleção o fato de terem sido as mais citadas nos grupos e nas entrevistas em profundidade, nos diferentes perfis de consumidoras.

\section{Os sentidos contemporâneos da joia}

A primeira e mais importante conclusão a que chegou a pesquisa é de que não há rejeição à joia por parte do público. Consideramos esse o mais importante dos achados, porque havia uma premissa aventada pelas associações que demandaram a investigação de que a principal causa para o declínio nas vendas do segmento seria uma desvalorização - rejeição, desinteresse - do produto joia em si.

Mas o que se verificou é que, ao contrário do que se podia supor ou inferir ainda no senso comum, a joia segue sendo um produto absolutamente sedutor nos seus aspectos estéticos, atraente na sua significação e providencial no seu uso cotidiano. Ao ponto de mesmo as não consumidoras de joias não chegarem a rejeitar o produto. Sentem-se, sim, distanciadas das joias, principalmente as mais jovens, mas não desprezam - ao contrário, demonstram reconhecer o valor e os sentidos implicados no uso e na posse da joia, mas acabam não sabendo como nem quando usar.

É interessante constatar nesse sentido, por exemplo, que o consumidor desse tipo de produto acaba desenvolvendo - a partir de um combinado de referências próprias, coletivas, sociais e culturais critérios que permitem classificar determinadas peças como joias ou não. São critérios imprecisos na sua constituição racional, difíceis de se explicarem por meio de um discurso verbal organizado, mas extremamente claros na sua função de separar o que é do que não é joia, de delimitar por meio dos significados o que fica dentro ou fora desse círculo - o que só evidencia a relevância simbólica desse tipo de produto e a força dos sentidos que adquirem na contemporaneidade.

Mercadorias, e coisas em geral, despertam, de modo independente, o interesse de diversos tipos de antropologia. (...). Na qualidade de objeto de valor, ocupam uma posição central na antropologia econômica e, com igual importância, na troca ou a antropologia social em geral, uma vez que são o instrumento do ato de representar. Analisar as coisas sob a perspectiva das mercadorias constitui um ponto de partida de 
grande utilidade para o interesse na cultura material, renovado pela orientação semiótica. (APPADURAl, 2008, p. 17).

Também tem crescido o entendimento de que o consumo e a circulação de objetos, produtos e marcas são uma prática comunicacional (PERNIOLA, 2005, p. 13). Esse entendimento encontra ressonância nos estudos de Appadurai (2008), Douglas \& Isherwood (2009) e Miller (2013). E, no caso da joia, a dimensão comunicativa está presente em todos os processos de produção e, ainda mais, nos rituais de consumo, como a empiria veio a reforçar.

Para as consumidoras mais frequentes, a joia funciona como um escudo, como uma proteção. Em uma sociedade caracterizada pelo esvaziamento das instituições socialmente incumbidas de sancionar os comportamentos dos indivíduos a partir de referenciais normativos claros e consensuais, o julgamento se torna uma prática pessoal, corriqueira e temida. Cada um se sente livre e incentivado para, a partir das suas conviç̧ões e da sua forma particular de enxergar a realidade, julgar (e quase sempre condenar) o comportamento alheio. $E$, se não estão na dimensão simbólica da cultura material e no próprio consumo os meios mais eficientes para se defender contra o julgamento que vem do outro, onde mais poderiam estar, considerando a transversalidade do consumo e a destradicionalização das instituições por que vimos passando nos últimos tempos (LIPOVETSKY, 2007, p. 50)? As palavras ditas por uma das participantes das discussões em grupo são inequívocas: "Sim, claro, fico imune. Quem é capaz de julgar tanto poder?", referindo-se ao uso de joias notadamente caras. É no uso de uma determinada peça de joalheria que se encontram as possibilidades de evitar julgamentos, demonstrar poder e alcançar (auto)proteção simbólica. “O que é um produto de significado? É aquele que dá a você a sensação de sentido na vida” (PONDÉ, 2017, p. 52).

Não chega a ser uma novidade que produtos caros, desejados por muitos e acessíveis a poucos alcancem esse elevado patamar de representação, alinhavando uma improvável e nem sempre uníssona afinidade entre sociólogos e antropólogos: muito já se discutiu sobre esse papel do consumo e da cultura material nas sociedades modernas e contemporâneas. O que não se esperava era que as joias pudessem alcançar tal tipo de significação, sobrepondo-se, inclusive, a produtos simbolicamente associados à diferenciação social.

Aparelhos celulares são produtos de extrema importância simbólica no contexto do consumo material contemporâneo. Por sua multifuncionalidade comunicacional, pela sua onipresença no cotidiano, 
pelo seu uso praticamente constante, quase sempre em contato direto com o corpo, e pela sua alta potência de sugerir status elevado por meio da marca e do design, podendo ainda receber aplicações de customização, tanto no aparelho em si quanto no seu sistema, acabam se transformando em signos dos mais valorizados. Entretanto, quando confrontados com as joias, os celulares acabam sendo remetidos pelos consumidores para um território semântico demarcado também pela efemeridade e pela massificação. Mais do que isso: celulares, assim como outros bens tecnológicos, representam ao mesmo tempo diversos sentidos negativos, como aprisionamento, excesso de informação, dependência, aniquilação da intimidade e da privacidade etc.

Serviços e experiências, por mais desejados socialmente, importantes mercadologicamente e expressivos simbolicamente, também acabam tendo seus significados relativizados pelos consumidores quando confrontados com os produtos da joalheria. Principalmente quando se trata da consumidora mais jovem, que enxerga esse tipo de consumo a partir da perspectiva de quem ganha e usufrui, não de quem paga ou contrata. Sim, viagens são cada vez mais profícuas no proporcionar de sensações marcantes e valorizadas; cursos, passeios, festivais e várias outras possibilidades mercadológicas de experiência vêm crescendo nessa dimensão abstrata e sensorial do consumo (LINDSTROM, 2007, MORAES, 2019). E crescem justamente por prescindirem de uma materialidade que se desgasta, que acaba ou que pode ser tomada. Pelo contrário: residindo ora na expectativa de antes, ora na memória de depois, esse tipo de consumo tende à idealização. Quanto mais distante cronologicamente do produto em si (festa, show, viagem), melhores são os sentidos envolvidos.

Mas e se a categoria de produto posta em comparação não tiver proximidade semântica com a obsolescência ou, pelo contrário, tiver o poder de suscitar a ideia da perenidade, da eternidade, de um tempo alongado que transcende a vida? É o que acaba acontecendo com a joia, pois reúne dois importantes atributos para a criação de valor e desejo junto ao público: uma significação simbólica relevante socialmente e uma materialidade pouco desgastável, com menor propensão à obsolescência. Parece-nos importante destacar que, a se considerar o que foi dito acima a partir da interpretação do que se discutiu nos grupos e nas entrevistas com as consumidoras, a joia poderia alcançar um importante patamar simbólico neste "mundo, que, a cada dia, se torna um deserto de sentido, enquanto se organiza mais e mais ao redor de uma sociedade de commodities invisíveis e de seus consumidores exigentes e empoderados" (PONDÉ, 2017, p. 53) 


\section{ALCEU}

ISSN: 2175-7402

Pensar em joia é também pensar em beleza - adorno, enfeite -, é reconhecer no seu uso uma inevitável busca pelo aprimoramento estético pessoal individual. O brilho do ouro, da platina, da esmeralda e do diamante são aspectos materiais altamente sugestivos desse sentido básico e indestrutível da joia: a capacidade de embelezar, seduzir e fazer chamar a atenção. E o que a gente quer, independentemente do contorno cultural que se esteja considerando, é beleza. Em uma sociedade atravessada pela idealização (LIPOVETSKY, 2015), que cada vez mais encara a realidade a partir da sua dimensão estética, a partir da sua aparência - em detrimento, como se sabe, da dimensão ética dos comportamentos ou da dimensão lógica, das visões de mundo -, os produtos e os procedimentos de embelezamento tendem a ocupar posição elevada na lista imaginária dos desejos.

Assim, joias, maquiagens, roupas, sapatos e acessórios, de um lado, e cirurgias plásticas, aplicações, cosméticos, remédios e agulhas, do outro, acabam representando tipos de produtos extremamente atraentes (BAUMAN, 2008), como foi possível identificar também durante a empiria. Antepondo dois dos mais claramente polarizantes deles - a joia e a cirurgia plástica -, o que se vê é que ambos, cada qual às suas possibilidades, expressam a busca incessante pela beleza. Só que a joia, novamente na comparação, acaba se equilibrando na ponderação semântica que define qualquer prática de consumo. Sugere perenidade, encanta, traz a ideia de raridade, desloca o consumidor para uma posição superior de exclusividade, mas não é definitiva, não provoca dor física, não oferece risco à saúde, não invade o corpo, não gera efeito colateral.

Quando pensada a partir de uma ritualística de troca, muito relacionada com os atos de dar e receber um presente, o potencial simbólico da joia cresce ainda mais. A partir do que se aprende de forma fundamental com Mauss (2017, p. 183) e de maneira mais prática com McCracken (2003), fica evidente o quanto a ritualística da troca, no universo da joalheria, é potente na sua capacidade de transferência de significados.

Frequentemente, o doador-do-presente escolhe um presente porque este possui as propriedades significativas que ele ou ela deseja ver transferidas para o receptor-do-presente. De fato, em muitas trocas de presentes intenciona-se que o receptor do presente seja também o receptor das propriedades simbólicas que o presente contém. (MCCRACKEN, 2003, p. 115)

O que se extrai por meio da interpretação da fala das consumidoras é surpreendente: na visão delas, a joia que se dá ou que se ganha de presente, pelo alto custo que normalmente envolve e por tudo o que ela representa na complexa dinâmica cultural da contemporaneidade, suscita os sentidos de esforço, 
envolvimento, confiança e, principalmente, afeto. Trata-se de uma conclusão importante, pois impensável sem o empreendimento da pesquisa, da associação entre a reflexão teórica e a prática empírica. Vejamos: é justamente por todas as suas "falhas", por tudo aquilo que poderia indicar seu declínio simbólico, que a joia se mantém forte na sua representação. É abrindo mão da funcionalidade (de um celular, por exemplo), é não podendo ser idealizada (como se faz com uma viagem), é sendo menos atraente e afinada às lentes e aos filtros das fotografias digitais que nos plasmam nas redes sociais que a joia consegue representar, nas relações pessoais que estabelece e materializa, o compromisso e o esforço. Em outras palavras: é no entendimento da sua significação, improvável e nada óbvia diante do contexto cultural em que estamos inseridos, que a joia cumpre sua função de vincular, produzir efeito de sentido e gerar significação.

\section{Joias e rituais de consumo}

A aplicação de um exercício de técnica projetiva realizado durante a pesquisa deixou evidente o quanto as associações à joia são positivas, relacionadas a independência, beleza, sofisticação, elegância etc. Para as consumidoras mais jovens, a joia está associada à entrada ao mundo adulto, enquanto para as mais velhas é a materialização da sua realização como mulher. Nota-se com alguma clareza o quanto o consumo das joias, em ambos os casos, é ritualístico, bem aos moldes que definem os autores clássicos (GENEPP, 2013; TURNER, 2013) e as aproximações com o consumo (TRINDADE e PEREZ, 2013, PEREZ, 2020). É a partir do seu consumo - ganhar, comprar, possuir, usar etc. - que a consumidora se conecta com os sentidos culturalmente constituídos que deseja.

O ritual é uma oportunidade para afirmar, evocar, assinalar ou revisar os símbolos e significados convencionados na ordem cultural. O ritual é, nesta medida, uma poderosa e versátil ferramenta para a manipulação do significado cultural. Sob a forma do clássico "rito de passagem", é usado para mover um indivíduo de uma categoria cultural de pessoa para outra, e deste modo um conjunto de propriedades simbólicas pode ser abandonado e um outro pode ser apropriado. (MCCRACKEN, 2003, p.114)

O principal problema da vida social é fixar significados de modo que fiquem estáveis por algum tempo. Sem modos convencionais de selecionar e fixar significados acordados, falta uma base consensual mínima para a sociedade. (...) Os rituais são convenções que constituem definições públicas visíveis. (...) Viver sem rituais é viver sem significados claros. (...) Os bens, nessa perspectiva, são acessórios rituais. (DOUGLAS \& ISHERWOOD, 2009, p. 112)

No caso específico investigado, a ritualística do consumo da joia se impõe como necessária à conexão com os sentidos do feminino. Pode funcionar como meio simbólico de acesso a uma concepção cultural de "mulher adulta", enfim enredada em sentidos como vaidade e autonomia. Podendo também 
reforçar, em um contexto de indeterminação generalizada, os sentidos de ser mulher. Abre-se aqui a possibilidade de uma grande, profunda, complexa, polêmica e necessária discussão sobre a relação entre o consumo e os novos sentidos do feminino na contemporaneidade. Não nos furtando ao desafio - novos trabalhos existem para novos problemas -, fizemos questão de destacar essa aproximação do consumo de joia com as práticas ritualísticas para atingir outro ponto importante da pesquisa.

Não se pode falar em ritual de consumo hoje em dia sem pensar ao mesmo tempo experiência de compra. É certo que os rituais de uso e de posse - os mais visíveis nessa relação simbólica das pessoas com os produtos - se dão mais em uma esfera íntima, social e cotidiana, longe do alcance efetivo das marcas ou dos fabricantes. Mas não se pode ignorar a importância que tem o processo de compra (busca, experimentação, comparação, aconselhamento) na construção dessa ritualística tão necessária a esse e a tantos outros mercados.

Nesse sentido, nota-se uma plena abertura do mercado de joias ao que se pode chamar de marketing de experiência ou de marketing sensorial. Benjamin Franklin (in LINDSTROM, 2007, epígrafe) deixa evidente a força da experiência sensível “Diga-me e eu esquecerei. Mostre-me e talvez eu lembre. Envolva-me e eu entenderei".

A abordagem do marketing sensorial consiste em tratar o cliente numa simbiose com a marca. $O$ desafio é penetrar na mente humana a um nível profundo, utilizando para o efeito estratégias sensoriais. Uma estratégia é definida como sensorial quando apela a um ou mais sentidos na mente humana. (RODRIGUES \& HULTÉN, 2014, p. 114)

Só que, no âmbito específico da investigação de que decorre este artigo, se revelou que a experiência de consumo de joia nem sempre é boa. O ritual de busca, por exemplo, está muito prejudicado.

Revestida de significados bem diversos da condição fabril dos bastidores, a área destinada ao público [das lojas] é aquela na qual impera a magia do consumo. Nela se multiplicam maravilhas, e uma soberana relação entre bens e pessoas se concretiza. (...) A loja se converte no que podemos chamar de um "espaço comunicacional". Nele, produtos viram bens de consumo ao adquirirem condição humana. (ROCHA, FRID \& CORBO, 2016, p. 169)

Por mais que disso se saiba, no caso específico das joalherias, não se exploram as muitas potencialidades dos ambientes de consumo. Uma vez que, na visão geral das pessoas - incluam-se aí fabricantes, lojistas e vendedores -, a joia é símbolo de compromisso, as práticas características do 
processo de busca de um produto acabam sendo impedidas. Os típicos comportamentos do "estou só olhando", "vim ver as novidades" e "sem compromisso" são impossíveis.

Acentua-se ainda mais esse distanciamento com o fato de que, por vezes, o vitrinismo das lojas não contribui no convite à visita ou na construção de sentido. Expondo as peças de modo quase sempre restrito, em espaços e suportes muito pequenos, implicam a necessidade de aproximação da consumidora mais corajosa e determinada. Diz-se corajosa porque, com essa aproximação, se corre o risco da abordagem imediata da vendedora da loja, que, numa prática recorrente do comércio, acaba gerando sentidos de intimidação.

Há na dinâmica ritualística certa sequencialidade, previsível e "obrigatória", que o mercado da joia parece ignorar ou não considerar. Assim como o noivado antecede o casamento, e o jejum precede o festejo, a busca é meio para a compra, a experimentação é condição para a efetivação do consumo. De modo que, se não houver um favorecimento desse tipo específico de ritual - como vêm fazendo os mais diversos setores do mercado, de concessionárias de automóveis a salões de beleza -, a conexão simbólica se esvazia e os sentidos da racionalidade se sobrepõem, o que inevitavelmente, se não impede, prejudica ou dificulta a decisão final em favor da joia.

\section{A função da publicidade no consumo da joia}

Outro destacado resultado da pesquisa é a constatação de que a joia não se basta como signo atrativo na contemporaneidade. Ela é "tudo de bom", como dizem as consumidoras mais entusiasmadas com o segmento, mas não é autossuficiente na sua produção de sentido. E nenhum produto ou bem o é. Como demonstram os antropólogos e semioticistas do consumo, é muito em função da sua contiguidade que se constituem os sentidos produzidos por determinado objeto. É na combinação desta coisa com aquela outra coisa que se alcançam os sentidos desejados. Sobretudo em um contexto mundial em que o individualismo cresce, porém, sendo o Brasil um país extremamente relacional, em que as práticas sociais são direcionadas a partir e para o outro, a justaposição de produtos é estratégia relevante nesse equilíbrio.

Só que o mercado de joias, em sua comunicação publicitária típica, parece seguir em outra direção. Não é raro - pelo contrário, é a regra - encontrarmos anúncios que, no afã de destacar as propriedades estéticas das peças, acabam as descontextualizando. Fundos infinitos e modelos despersonalizados (sem expressão ou atitude, ou seja, sem vida) são a manifestação máxima desse tipo de comunicação que, como 
se viu na pesquisa, mais afasta e cria vazios semânticos do que seduz, encanta, convida ou atrai. Quantas peças publicitárias de joias (em meios tradicionais ou em redes sociais, tanto faz) não se sustentam no clichê estético do corpo nu coberto apenas com um colar, uma pulseira ou um anel?

Enquanto marcas de outros segmentos apresentam seus produtos contextualizados, com outros inseridos em uma cenografia das mais sugestivas, com modelos em situações de uso, a joia insiste na ideia de ser apresentada sozinha, isolada, sem contexto, nessa estética museológica, portanto distanciada. A análise semiótica das campanhas das marcas já elencadas comprova tudo isso. A joia aparece destacada, valorizando suas formas e sua beleza? Sim. Mas não se aproxima semanticamente do consumidor. Encanta os olhos, mas não sugere uso, além de ser sempre muito autorreferencial. É importante que se considere o que afirmam Everardo Rocha e Cláudia Pereira (2013, p. 21), sobre uma das funções da publicidade:

Entre as múltiplas narrativas que constroem o universo simbólico em que vivemos, uma delas pode ser
tomada como absolutamente central no imaginário moderno-contemporâneo. Trata-se da narrativa
publicitária. (...) A publicidade é a narrativa do consumo, ela nos ensina a consumir, confere significado aos
bens, lhes atribui valor simbólico, nos ajuda a classificar as coisas e as pessoas, reproduz nossos valores e
crenças. O consumo, como fenômeno complexo, pautado na vala que existe entre uma existência individual e o pertencimento a um coletivo, se efetiva em termos simbólicos no dinamismo do cotidiano. De modo que uma das funções mais urgentes para a publicidade no contemporâneo é dar sentido aos produtos e às marcas justamente nessa realidade complexa e desafiadora. Podemos nem nos dar conta, mas só compramos determinada peça de roupa porque aprendemos - com as novelas, com os amigos, com os desfiles de moda, com o Instagram, com as pessoas na rua e, ainda hoje, com a publicidade - como, onde, com o quê e com quem usá-la. A justaposição de um produto com outro, a atitude desejada, o gestual previsto, o contexto demandante, a ocasião propícia - tudo isso se constrói culturalmente por força dos mecanismos que constituem o sistema cultural e mercadológico em que estamos todos, consumidores e marcas, inseridos.

Uma possibilidade que pode ser bastante promissora para o mercado de joia é aprender com o didatismo e o efeito mimético que sustenta o consumo de moda há muito tempo. Por mais que possa haver ênfase no lançamento de uma nova bolsa de marca ou de um novo modelo de óculos, por exemplo, toda a sua comunicação é contextualizada, integrando produto-conceito-consumidor. Não se trata de explicitar atributos estéticos ou simbólicos, reforçando sentidos já incrustados, com o perdão do 


\section{ALCEU}

ISSN: $2175-7402$

trocadilho, nos produtos em questão. Trata-se, isto sim, de demonstrar, de forma didática e mimética, de que forma aquele bracelete diferente ou aquele anel mais ousado podem se inserir no dia a dia do consumidor, atribuindo-lhe (ao consumidor) os sentidos positivos que ele tanto anseia para a sua vida (PEREZ e POMPEU, 2020). Sites de um varejo menos prestigiados ou de categorias de produto menos vaidosas de si já vêm experimentando uma outra estética, dando novas e importantes funções à publicidade. Ao apresentarem seus produtos em cenas que emulam o banal do cotidiano, como que em flagras ou posts despretensiosos - e, por favor, não confundir aqui com algo a que se acostumou chamar de street style -, demonstram como os produtos devem ser usados. E não se pode negar que o efeito seja positivo. Numa sociedade que tudo aprende a partir dos conteúdos que passam instantaneamente pelas telas, esse tipo de publicidade cumpre plenamente seu sentido, de amalgamar os produtos com os sentidos.

Outra constatação que emergiu da análise semiótica da comunicação das marcas é que há uma confusão conceitual entre sedução e mistério. Não são sinônimos. Na busca por valorizar uma determinada concepção de sensualidade, pautada em um suposto clima de mostra-esconde, as marcas acabam partindo para uma comunicação hermética demais, um conceitual vazio, sem associações de sentido. De fato, a sedução, a sensualidade e a associação do consumo com o sexo são caminhos estratégicos consagrados na publicidade. Mas, no caso específico das joias, o que a pesquisa mostrou é que, se não se alcança essa geração de sentido, tampouco se alcançam outros valores desejados. A busca pela ideia da sedução resvala na armadilha do mistério. Há que haver um vínculo claro entre, por mais abstrato que venha a ser, o tema de uma determinada coleção de produtos, a joia que está sendo oferecida e o consumidor - o que raramente acontece.

\section{Considerações finais}

Retomando o objetivo que nos levou à pesquisa aqui apresentada, notamos que um aprendizado importante foi a constatação da inexistência de rejeição a joia, pressuposto inicial. A partir dessa constatação inicial, buscamos aprofundar os sentidos das joias para as consumidoras, o que se revelou um caminho extremamente rentável sobre os rituais de consumo, com privilégio para o ritual de uso e os momentos em que a joia foi presenteada, principalmente pelo viés de quem recebeu o presente. Os distanciamentos simbólicos das joias, presentes nas consumidoras mais jovens, estavam fundamentados 
na sistemática comunicação publicitária autorreferencial das joias, que se apresentam descontextualizadas de uso, como pôde ser verificado nas análises semióticas das marcas de joia, em que a centralidade do objeto joia se bastava, não criando narrativas sígnicas por meio das experiências de uso, por exemplo. Esse foi outro resultado da pesquisa com grande impacto para o pensamento semiótico acerca da joia, com possibilidades rentáveis de atuação mercadológica em ações em produto e, principalmente, publicitárias.

Embora nos pareça que os resultados apresentados acima tenham relevância, como já dito, na sua potencialidade de aplicação prática e na sua proposta de reflexão teórica, não se minimizam as limitações inerentes a esta pesquisa. Tentou-se ao longo do texto demonstrar de que forma os conhecimentos teóricos do consumo e da publicidade podem contribuir tanto no entendimento dos complexos processos por meio dos quais se dão as práticas de consumo na contemporaneidade quanto na eventual elaboração de estratégias que possam contribuir com o desenvolvimento do mercado de joias. A partir de pesquisa empírica de natureza qualitativa realizada com o público consumidor e com vendedoras de joias, incluindo também análise semiótica de materiais de marcas de joias, chegamos a algumas interpretações que, embasadas em referencial teórico abrangente da antropologia e da semiótica, podem ser ao mesmo tempo relevantes ao campo da comunicação e ao mercado joalheiro. Mesmo assim, apontam-se a seguir possibilidades de continuidade e complementariedade a este estudo.

Outros perfis de públicos, uma representatividade maior de outros tipos de marca: tanto maior possa ser o material-base de que partem as análises, as interpretações e de que se extraem as conclusões, mais robustos e válidos tendem a ser os resultados. No nosso caso específico, tivemos que lidar com limitações de tempo, de orçamento e de recursos técnicos. Porém, dentro do que foi possível, buscou-se sempre o máximo aproveitamento dos métodos e das técnicas utilizadas, mantendo, ao mesmo tempo, fidelidade ao rigor que caracteriza as pesquisas acadêmicas de sempre e respeito aos princípios metodológicos mais contemporâneos (CANEVACCI, 2013), com abertura aos estupores que porventura apareceram.

E que, nesse sentido de se suprirem as limitações, outras pesquisas possam ser realizadas, vindo a ampliar seus entendimentos e aprofundar suas contribuições. Seriam bem-vindas, por exemplo, outras análises semióticas - de outros materiais, como vitrines, catálogos, ambiência de loja, produtos. Assim como também só viriam a somar pesquisas de caráter quantitativo, dando clareza numérica e estatística à dimensão do que aqui se levanta como resultado. 


\section{ALCEU}

É reconhecido o caráter crítico do contexto atual em diversas frentes, sobretudo naquelas que envolvem aspectos sociais, culturais e econômicos (POMPEU, 2016), impactando diretamente o mercado e oferecendo novos desafios ao meio acadêmico. Se, no passado recente, já tínhamos um mercado consumidor em si diverso, hoje temos consumidores em um patamar inédito de individualização (HAN, 2018, p. 115), que pode assumir as mais variadas feições, com necessidades igualmente imprevisíveis e diversificadas. Nesse sentido, pensando no consumidor de joias, mas com refração para diversos outros mercados, é fundamental levar em conta que no Brasil convivemos com todas as possibilidades de consumidor: com o consumidor tradicional, que expressa os valores clássicos, conservadores, que estão focados nos prazeres íntimos e na autossuficiência. Há o consumidor que valoriza a ostentação, que é pautado no exagero, na exacerbação dos signos da marca, que enxerga na joia um meio de demarcação de status social elevado e riqueza, muito centrado no consumo, incluindo o de joia, para o olhar do outro. E há ainda o consumidor mais conectado com os valores do contemporâneo, em busca de valores humanistas, ecológicos e éticos. E, para dar conta dessa diversidade, a joia precisa expressar os valores que as pessoas desejam, romper com a ideia de que o material é um limitador, apostar nas linguagens híbridas e jovens, explorar processos artesanais, míticos e tecnológicos.

Trata-se de esforços grandes, complexos, diversos e custosos. Mas que têm em seu cerne o entendimento do consumidor. Um consumidor que, ao contrário do que chegam a afirmar gurus açodados, não demonstra prescindir da materialidade. Ao contrário: "quanto mais a humanidade busca alcançar a conceitualização do imaterial, mais importante é a forma específica de sua materialização" (MILLER, 2013, p.114). Daí que os estudos - como este - que entrelaçam consumo, cultura material e comunicação sejam tão relevantes.

Faz tempo que a relação entre marcas e indivíduos já não se pauta nos princípios mercadológicos que nos trouxeram até os dias atuais. Hoje, parece haver uma nova negociação simbólica entre as instituições fomentadoras do consumo e as pessoas que procuram encontrar sentido nas coisas que compram. Han (2018, p. 12) nos diz que "a comunicação digital desconstrói a distância de modo generalizado. A desconstrução da distância espacial acompanha a erosão da distância mental". Sendo essas afirmações quase inegáveis, fica fácil entender o crescimento da expectativa por parte dos consumidores e o aumento dos desafios que se impõem às marcas. Cada vez mais próximos, um ao alcance do outro em questão de poucos segundos e rápidos toques, porém nem sempre (quase nunca) 
concordando em princípios, objetivos e lógicas - afinal, estamos falando de pessoas e empresas -, o atrito, a repulsa e a incompreensão se tornam mais fáceis. Daí que o entendimento, o ajustamento, a afinidade e o falar a mesma língua sejam tão necessários hoje em dia ao sucesso de qualquer marca ou empresa que queira prosperar por meio do consumo, reforçando ainda mais o lugar da publicidade nesse processo.

Clotilde Perez

ORCID: https://orcid.org/0000-0003-3062-4087 Universidade de São Paulo, Escola de Comunicação e Artes, São Paulo (SP), Brasil. Doutora em Comunicação e Semiótica pela PUC-SP E-mail: cloperez@terra.com.br

Bruno Pompeu

ORCID: https://orcid.org/0000-0002-2829-5803 Universidade de São Paulo, Escola de Comunicação e Artes, São Paulo (SP), Brasil. Doutor em Ciências da Comunicação pela ECA-USP E-mail: brupompeu@gmail.com

Recebido em: 18 de abril de 2020.

Aprovado em: 31 de agosto de 2020.

\section{Referências:}

APPADURAI, Arjun. A vida social das coisas: as mercadorias sob uma perspectiva cultural. Rio de Janeiro: EdUFF, 2008.

ARAUJO, F.F.; TINOCO, C.F. A Influência da Religião no Comportamento do Consumidor: Um estudo exploratório do consumo de produtos judaicos. Revista Alceu, v. 16, n.31, p. 38-61, 2015.

BAUER, Martin W.; GASKELL, George. Pesquisa qualitativa com texto, imagem e som: um manual prático. Petrópolis: Vozes, 2010.

BAUMAN, Zygmunt. Vida para consumo: a transformação das pessoas em mercadoria. Rio de Janeiro: Zahar, 2008.

. Modernidade líquida. Rio de Janeiro: Zahar, 2001. 
BLACK, J. A. A history of jewelry: five thousand years. New York: Random House, 1998.

BRAZIL EXPRESSIONS. Moda Biju Brasil. Fashion Business. Rio de Janeiro: Ajorio/IBGM/ FeComércio, 2007.

CANEVACCI, Massimo. O fetichismo metodológico tem o poder de mesclar os dois clássicos elementos da filosofia ocidental: sujeito e objeto. Matrizes, São Paulo, ano 7 - n. 1, p.169-178, jan-jun. 2013.

CARDOSO, R. Design para um mundo complexo. São Paulo: Cosac Naify, 2012.

COSTA, Maria Eugência B. Grupo focal. In: DUARTE, Jorge; BARROS, Antônio (orgs.). Métodos e técnicas de pesquisa em comunicação. São Paulo: Atlas, 2012.

DAYÉ, C.; CORNEJO, C.; COSTA, E. Joalheria no Brasil: história, mercado e ofício. São Paulo: Disal, 2017.

DOUGLAS, Mary.; ISHERWOOD, Baron. 0 mundo dos bens: para uma antropologia do consumo. Rio de Janeiro: UFRJ, 2009.

DUARTE, Jorge. Entrevista em profundidade. In: DUARTE, Jorge; BARROS, Antônio (orgs.). Métodos e técnicas de pesquisa em comunicação. São Paulo: Atlas, 2012.

É DO RIO! Guia dos criadores de joias e bijuterias do Rio de Janeiro. Rio de Janeiro, 2013

EICHHORN-JOHANNSEN, M. et al. (ed.). 25.000 years of jewelry. New York: Prestel, 2013.

GENEPP, Arnold Van. Os ritos de passagem. São Paulo: Vozes, 2013.

GIDDENS, Anthony. As consequências da modernidade. São Paulo: Unesp, 1991.

GOLA, E. A joia: história e design. São Paulo: Senac, 2008.

HAN, Byoung. No enxame: perspectivas do digital. Petrópolis: Vozes, 2018.

. A agonia de Eros. Petrópolis: Vozes, 2017.

LINDSTROM, Martin. Brandsense, a marca multissensorial. Porto Alegre: Bookman, 2007

LIPOVETSKY, Gilles. A estetização do mundo: viver na era do capitalismo artista. São Paulo: Companhia das Letras, 2015.

A felicidade paradoxal: ensaio sobre a sociedade de hiperconsumo. São Paulo: Companhia das Letras, 2007.

LIPOVETSKY, Gilles; CHARLES, S. Os tempos hipermodernos. São Paulo: Barcarolla, 2004.

LYOTARD, Jean Fraçois. A condição pós-moderna. 12. ed. Rio de Janeiro: José Olympio, 2010.

MALHOTRA, Naresh. Pesquisa de marketing: uma orientação aplicada. Porto Alegre: Bookman, 2012. 
MAUSS, Marcel. Ensaio sobre a dádiva. In: MAUSS, Marcel. Sociologia e antropologia. São Paulo: Ubu, 2017.

MCCRACKEN, Grant. Cultura e Consumo. Rio de Janeiro: Mauad, 2003.

MEDINA, Cremilda de Araújo. Entrevista: o diálogo possível. São Paulo: Ática,1990.

MELO, D. F.; SOUZA, G.H.S.; COSTA, A.C.S.; LIMA, N.C. Perfil, Hábitos de Consumo e Motivações de Compra: uma Pesquisa de Mercado Aplicada ao Setor de Bijuterias. Revista Pensamento Contemporâneo em Administração, v. 10, n.4, p. 130-147, 2016.

MILLER, Daniel. Trecos, troços e coisas: estudos antropológicos sobre a cultura material. Rio de Janeiro: Zahar, 2013.

MOL, Adriano. (org). Manual de Lapidação diferenciada de gemas. Brasília: Athalaia ed., 2009.

MORAES, Rosana. Marketing e a arte de luxo na era da experiência. Rio de Janeiro: FGV, 2019

PEIRCE, Charles. Semiótica. 2. ed. São Paulo: Perspectiva, 1999.

PEREZ, Clotilde. Signos da marca: expressividade e sensorialidade. São Paulo: Pioneira Thomson Learning, 2004.

. Há limites para o consumo? São Paulo: Estação das Letras e Cores, 2020

PEREZ, Clotilde \& POMPEU, Bruno. Moda mimética, desviante e criativa: em busca da secundidade perdida. Barcelona: Revista DeSignis, vol. 32, jan-jun 2020, pp. 49-62

PERNIOLA, Mario. O sex appeal do inorgânico. São Paulo: Nobel/ECA, 2005

PESQUISA NACIONAL DO MERCADO CONSUMIDOR DE JOIAS. São Paulo: IBGM, 2005.

PIRATININGA, Luiz Celso de. Publicidade: arte ou artifício? São Paulo: T. A. Queiroz, 1994.

POMPEU, Bruno. Consumo de classe alta e consumo de classe baixa: os dois lados do consumo brasileiro na publicidade contemporânea. In: COGO, D.; ROCHA, R. de M.; HOFF, T. (orgs.). 0 que é consumo: comunicação, dinâmicas produtivas e constituição de subjetividades. Porto Alegre: Sulina, 2016.

PONDÉ, Luiz Felipe. Marketing existencial: a produção de bens de significado no mundo contemporâneo. São Paulo: Três Estrelas, 2017.

ROCHA, Everardo; FRID, Marina; CORBO, William. O paraíso do consumo: Émile Zola, a magia e os grandes magazines. Rio de Janeiro: Mauad X, 2016.

ROCHA, Everardo; PEREIRA, Cláudia. De guaraná, namoro e gente moça: interpretação antropológica e narrativa publicitária. In: ROCHA, Everardo; PEREIRA, Cláudia (orgs.). Cultura e imaginação publicitária. Rio de Janeiro: Mauad X, 2013. 
RODRIGUES, Clarinda; HUKTÉN, Bertil. Marketing sensorial. In: BRITO, Carlos Melo; LENCASTRE, Paulo de (orgs.). Novos horizontes do marketing. Alfragide (Portugal): D. Quixote, 2014.

SANTAELLA, Lucia. A teoria geral dos signos: como as linguagens significam as coisas. São Paulo: Pioneira Thomson, 2004a.

. Semiótica aplicada. São Paulo: Pioneira Thomson Learning, 2004b.

SANTOS, Rita. Joias, fundamento, processos e técnicas. São Paulo: Senac, 2017

SOARES, Maria Regina Machado. A joia do Rio. Rio de Janeiro: Senac, 2001.

TAIT, Hugh. 7.000 years of jewellery. Richmond: Firefly, 2008.

TRINDADE, Eneus; PEREZ, Clotilde. Rituais de Consumo: dispositivos midiáticos de

articulação de vínculos de sentidos entre marcas e consumidores. In Anais XXII Encontro Compós. Salvador: UFBA/Compós, 2013.

TURNER, Victor. O processo ritual: estrutura e antiestrutura. São Paulo: Vozes, 2013.

YASUDA, Aurora; OLIVEIRA, Diva Maria T. de. Pesquisa de marketing: guia para a prática de pesquisa de mercado. São Paulo: Cengage, 2012.

\section{Resumo}

São complexas e cada vez mais desafiadoras as relações estabelecidas no âmbito do consumo. Como demonstram as teorias (sociologia e antropologia), o consumo envolve em uma lógica ritualística, mercadológica, vinculativa e relacional uma dimensão simbólica (dos significados), uma dimensão material (dos produtos) e uma dimensão humana (dos consumidores). Este artigo deriva de um esforço investigativo que abarca teoria e empiria, procurando entender os dilemas e os desafios do consumo de joias nos dias atuais. A partir do estudo realizado, de abordagem qualitativa e paradigma teórico interpretativista, propomos aqui discussões e reflexões sobre o desenvolvimento do mercado joalheiro no Brasil, o consumo simbólico na contemporaneidade e o efetivo papel da comunicação publicitária nas dinâmicas do consumo.

Palavras-chave: Joia. Sentidos da joia. Consumo. Cultura material. Semiótica. 


\section{Abstract}

The relationship established in the field consumption is complex and increasingly challenging. As theories show (Sociology and Antropology), consumption involves in a ritualistic, market, conjunctive and relational logic, a symbolic dimension (of meanings), a material dimension (of products) and a human dimension (of consumers). This article derives from an investigative effort that embraces theory and empiricism, trying to understand the dilemmas and the challenges of the consumption of jewels in the present days. From the study carried out with a qualitative approach and interpretative theoretical paradigm, we propose here discussions and reflections about the development on the Brazilian jeweler market, the symbolic consumption in contemporaneity and the effective role of advertising communication in the dynamics of consumption.

Keywords: Jewelry. Senses of jewelry. Consumption. Material culture. Semiotics.

\section{Resumen}

Las relaciones establecidas en el contexto del consumo son complejas y cada vez más desafiantes. Como demuestran las teorías (sociología y antropología), el consumo implica, en una lógica ritualista, de marketing, vinculante y relacional, una dimensión simbólica (de significados), una dimensión material (de productos) y una dimensión humana (de los consumidores). Este artículo deriva de un esfuerzo de investigación que abarca la teoría y el empirismo, buscando comprender los dilemas y desafíos del consumo de joyas en la actualidad. Con base en el estudio realizado, con un enfoque cualitativo y un paradigma teórico interpretativo, proponemos aquí discusiones y reflexiones sobre el desarrollo del mercado de la joyería en Brasil, el consumo simbólico en los tiempos contemporáneos y el papel efectivo de las relaciones establecidas por la comunicación publicitaria en la dinámica del consumo.

Palabras clave: Joyería. Sentidos de la joya. Consumo. Cultura material. Semiotica.

Este artigo é publicado em acesso aberto (Open Access) sob a licença Creative Commons Attribution Non-Commercial (CC-BY-NC 4.0), que permite que outros remixem, adaptem e criem a partir do seu trabalho para fins não comerciais, e embora os novos trabalhos tenham de lhe atribuir o devido crédito e não possam ser usados para fins comerciais, os usuários não têm de licenciar esses trabalhos derivados sob os mesmos termos. 